\title{
Mirror-image phenomenon in Turkish monozygotic twins: A report of 3 cases
}

\section{Fenomen lustrzanych odbić u tureckich monozygotycznych bliźniąt - opis trzech przypadków}

\author{
Damla Torul ${ }^{A-F}$, Mehmet Melih Omezli ${ }^{\mathrm{A}, \mathrm{C}, \mathrm{E}, \mathrm{F}}$ \\ Department of Oral and Maxillofacial Surgery, Faculty of Dentistry, Ordu University, Turkey \\ A - research concept and design; $\mathrm{B}$ - collection and/or assembly of data; $\mathrm{C}$ - data analysis and interpretation; \\ $D$ - writing the article; $E$ - critical revision of the article; $F$ - final approval of the article
}

\section{Address for correspondence \\ Damla Torul \\ E-mail: damlatorul@gmail.com}

\section{Funding sources}

None declared

Conflict of interest

None declared

\section{Acknowledgements}

The authors would like to thank Taha Alpaydin, DDS, from the Department of Orthodontics, Faculty of Dentistry at Ordu University, Turkey, for his valuable help during the preparation of the photographs of the twins.

Received on August 30, 2019

Reviewed on 0ctober 5, 2019

Accepted on November 15, 2019

Published online on June 30, 2020

\begin{abstract}
Due to the special circumstances and the pre-natal environment in twin gestations, disruptions in the development of the embryo are more frequently observed in twin births as compared to singleton births. Twin research provides an excellent model to explore the etiology of disruptions in craniofacial biology. Mirror imaging (MI) is a special manifestation of twinning, and the elucidation of the etiology of this phenomenon is important to understand the biological mechanisms which underlie congenital defects, like orofacial clefts, and to provide insight into left-right asymmetry.

The aim of this paper was, therefore, to present 3 pairs of Turkish monozygotic (MZ) twins with MI dental features, and to contribute to the knowledge of the Ml phenomenon in the literature. We examined 2 male and 1 female MZ twin pairs clinically and radiographically in terms of their Ml features. Mirrorimage features in dental and other ectodermal structures were detected in all the twins. Understanding the biological mechanisms of Ml provides broad insight into preventive measures and treatment protocols. Furthermore, the presence of Ml features may lead to the detection of other Ml pathologies in twins.
\end{abstract}

Key words: asymmetry, identical twins, mirror image

Słowa kluczowe: asymetria, bliźnięta identyczne, lustrzane odbicie

Cite as

Torul D, Omezli MM. Mirror-image phenomenon in Turkish monozygotic twins: A report of 3 cases. Dent Med Probl. 2020;57(2):207-211. doi:10.17219/dmp/114248

DOI

$10.17219 / \mathrm{dmp} / 114248$

Copyright

○ 2020 by Wroclaw Medical University

This is an article distributed under the terms of the

Creative Commons Attribution 3.0 Unported License (CC BY 3.0)

(https://creativecommons.org/licenses/by/3.0/). 


\section{Introduction}

Over the centuries, twinning and its unique features have been a valuable source for exploring the relative contributions of nature and nurture to various phenotypic traits and pathologies in humans. ${ }^{1,2}$ Mirror imaging (MI) is a special manifestation of twinning, also known as reverse asymmetry, in which one member of a twin pair 'mirrors' the other in 1 or more features. ${ }^{1,3,4}$ The underlying biological mechanisms of MI are still not clear, but preliminary evidence in the literature suggests that reverse asymmetry may be a reflection of a genetically mediated embryological event. Also, it has been suggested that MI is epigenetically linked to the timing of twinning, and therefore the type of placentation. ${ }^{4,5}$ Some aspects of this phenomenon are estimated to occur in $25 \%$ of monozygotic (MZ) twins and are typically observed in the tissues derived from the ectoderm; they comprise dentation, hair whorls, dermatoglyphics, eyesight, nevi, handedness, and the cerebral hemispheres. ${ }^{1,3,6}$ In the literature, several MI features and pathologies have been reported. ${ }^{3,6-10}$

The aim of this article was to present 3 pairs of Turkish MZ twins with MI dental features, and to contribute information about the MI phenomenon to the literature.

\section{Case report}

Two male and 1 female MZ twin pairs (5, 9 and 10 years old, respectively) were referred to the Department of Oral and Maxillofacial Surgery, Faculty of Dentistry at Ordu University in Turkey for routine examinations. Written informed consent to participate in the study was obtained from the parents of the twins. The zygosity of the twins was determined according to a standard zygosity questionnaire and blood groups. ${ }^{11}$ Handedness was measured with a hand preference (HP) inventory based on the Edinburgh Handedness Inventory. ${ }^{12}$
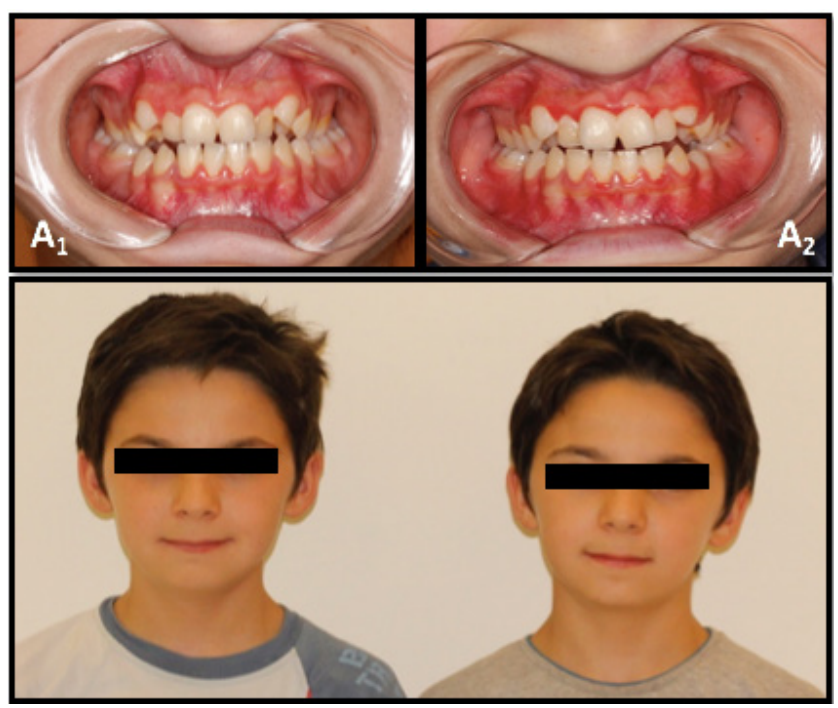

Fig. 1. Front view of twins $A_{1}$ and $A_{2}$
Hand use was evaluated during drawing, writing, using scissors, throwing a ball, cutting with a knife, using a spoon, using a toothbrush, using a broom, taking a lid off a box, and dealing cards. The inventory awarded 2 points for each right-handed action, 0 points for lefthanded actions, and 1 point for mixed or unclear preference, with the total score ranging from 0 (left-handed) to 20 (right-handed).

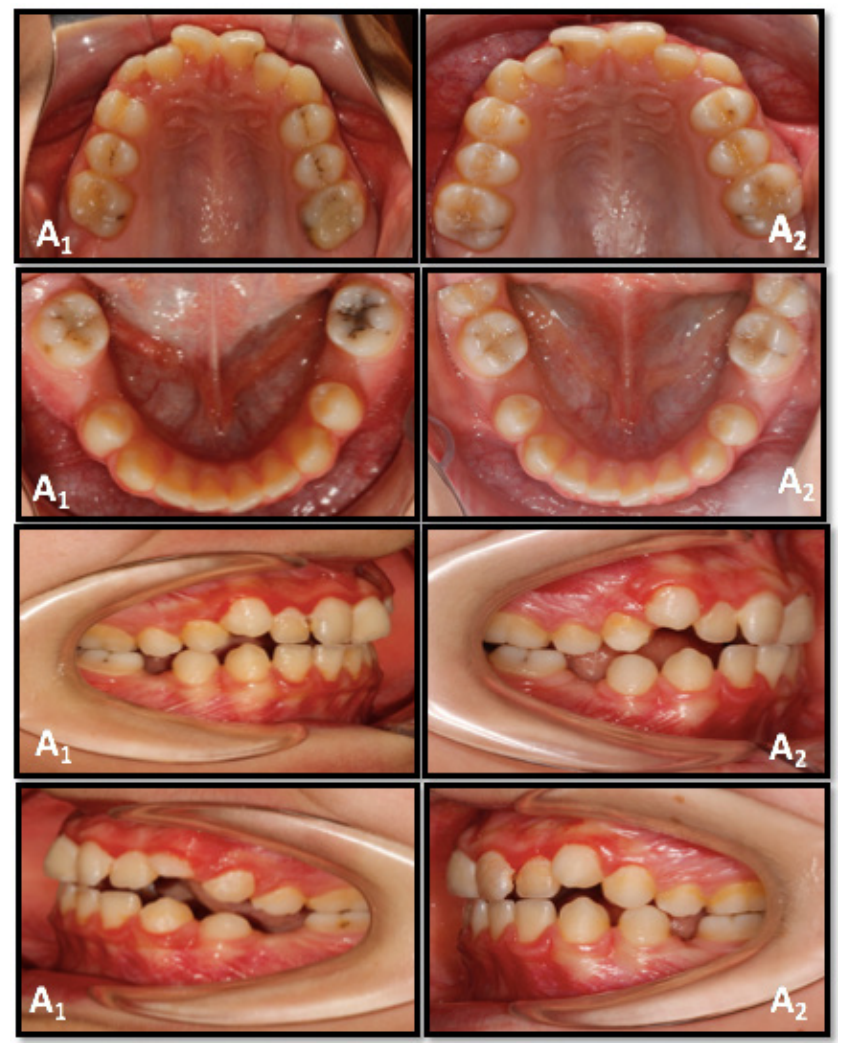

Fig. 2. Intraoral photographs of $A_{1}$ and $A_{2}$

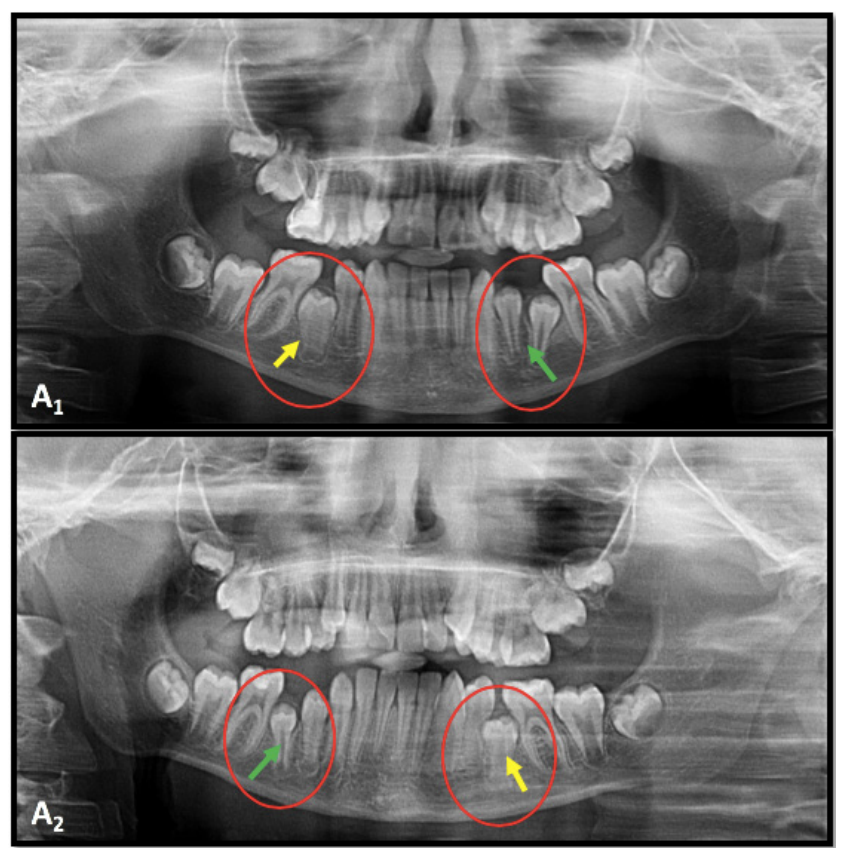

Fig. 3. Panoramic radiographs showing the mirror-image (MI) dental features of $A_{1}$ and $A_{2}$ (arrows) 
The twins' medical and dental histories were noncontributory. All 3 twin pairs were subjected to clinical and radiographic examinations. Panoramic and lateral cephalometric radiographs were obtained from all 3 pairs.
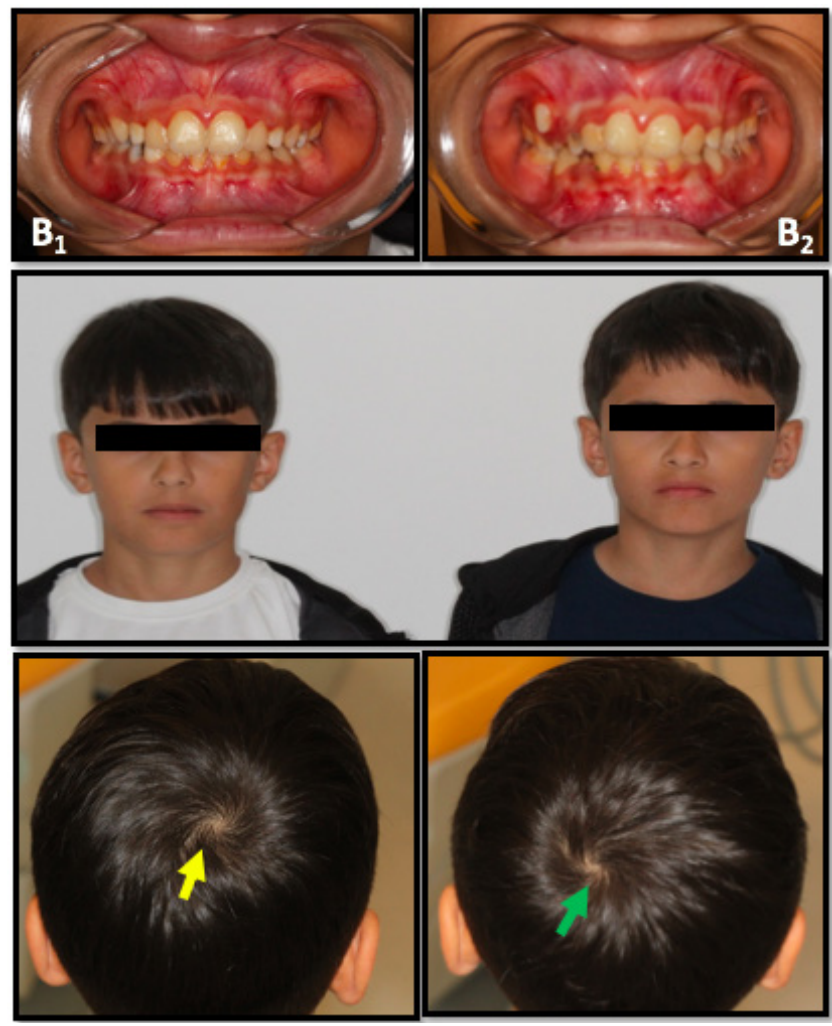

Fig. 4. Front view and hair whorls of twins $B_{1}$ and $B_{2}$

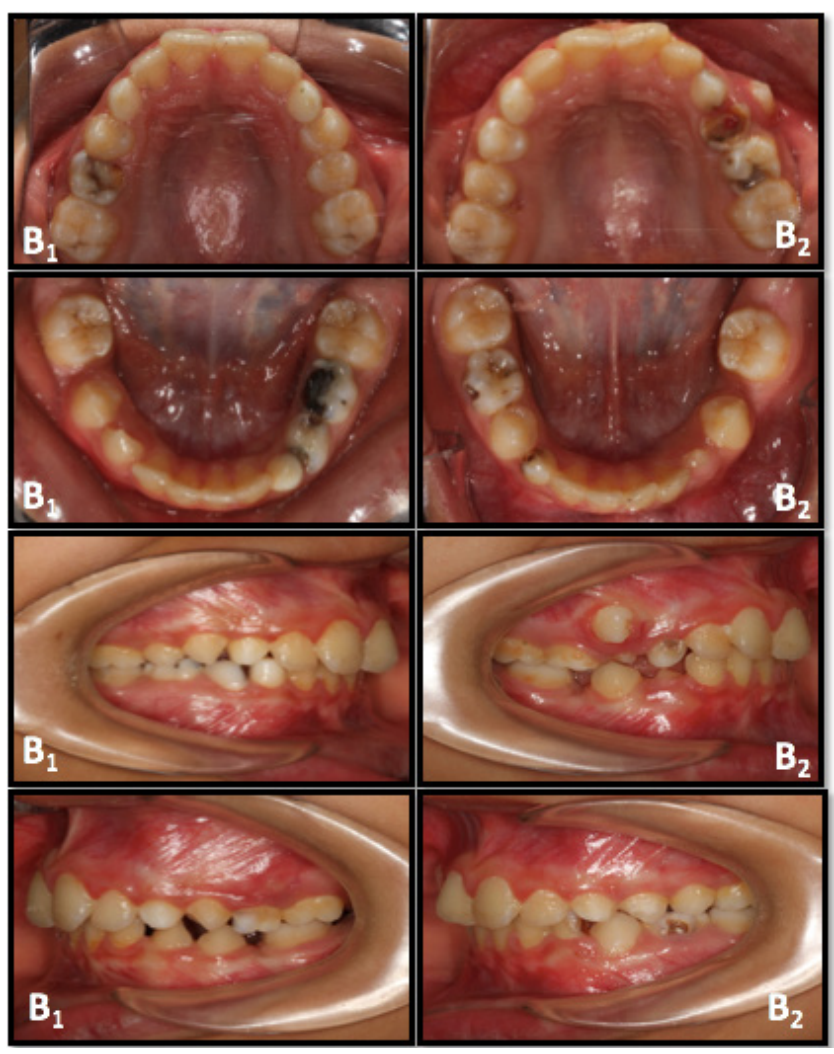

Fig. 5. Intraoral photographs of $B_{1}$ and $B_{2}$
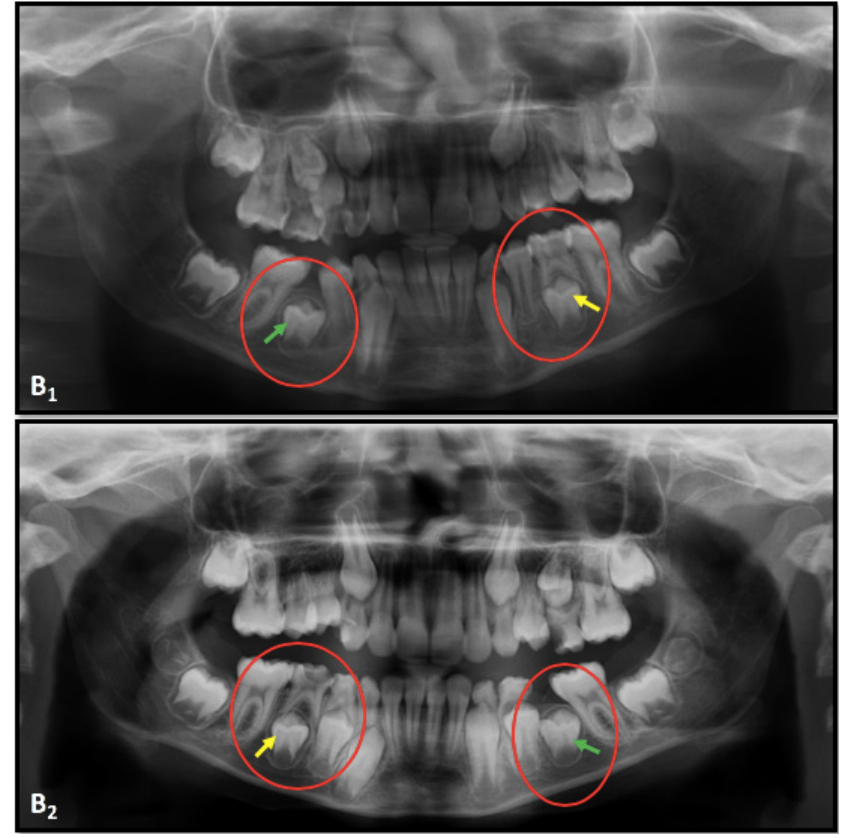

Fig. 6. Panoramic radiographs showing the $\mathrm{Ml}$ dental features of $\mathrm{B}_{1}$ and $\mathrm{B}_{2}$ (arrows)

Clinically, twins $\mathrm{A}_{1}$ and $\mathrm{A}_{2}$ were at the mixed dentition stage, with the mandibular premolar teeth showing MI asymmetries (Fig. 1-3). Also, $\mathrm{A}_{1}$ was right-handed and kicked with his right foot, whereas $A_{2}$ was left-handed and kicked with his left foot.

Twins $B_{1}$ and $B_{2}$ were also at the mixed dentition stage and had MI features in their dentition. The hair whorls of $B_{1}$ and $B_{2}$ were in opposite directions: one's clockwise, and the other's counter-clockwise (Fig. 4-6).

Twins $C_{1}$ and $C_{2}$ were also at the mixed dentition stage and showed MI features in the eruption pattern of their mandibular central incisor teeth (Fig. 7-9).
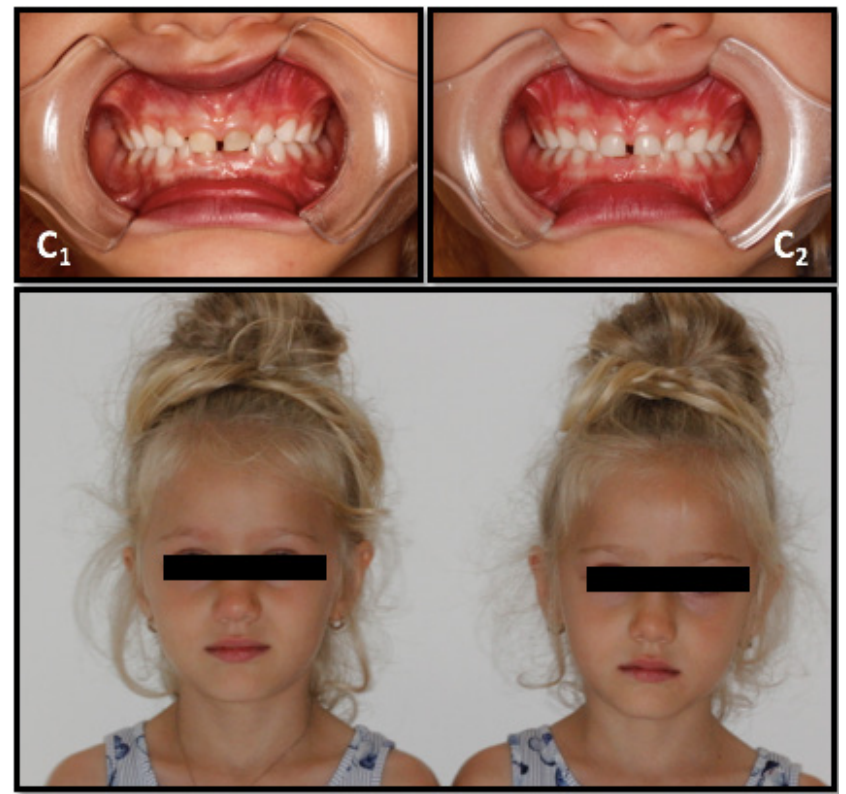

Fig. 7. Front view of twins $C_{1}$ and $C_{2}$ 


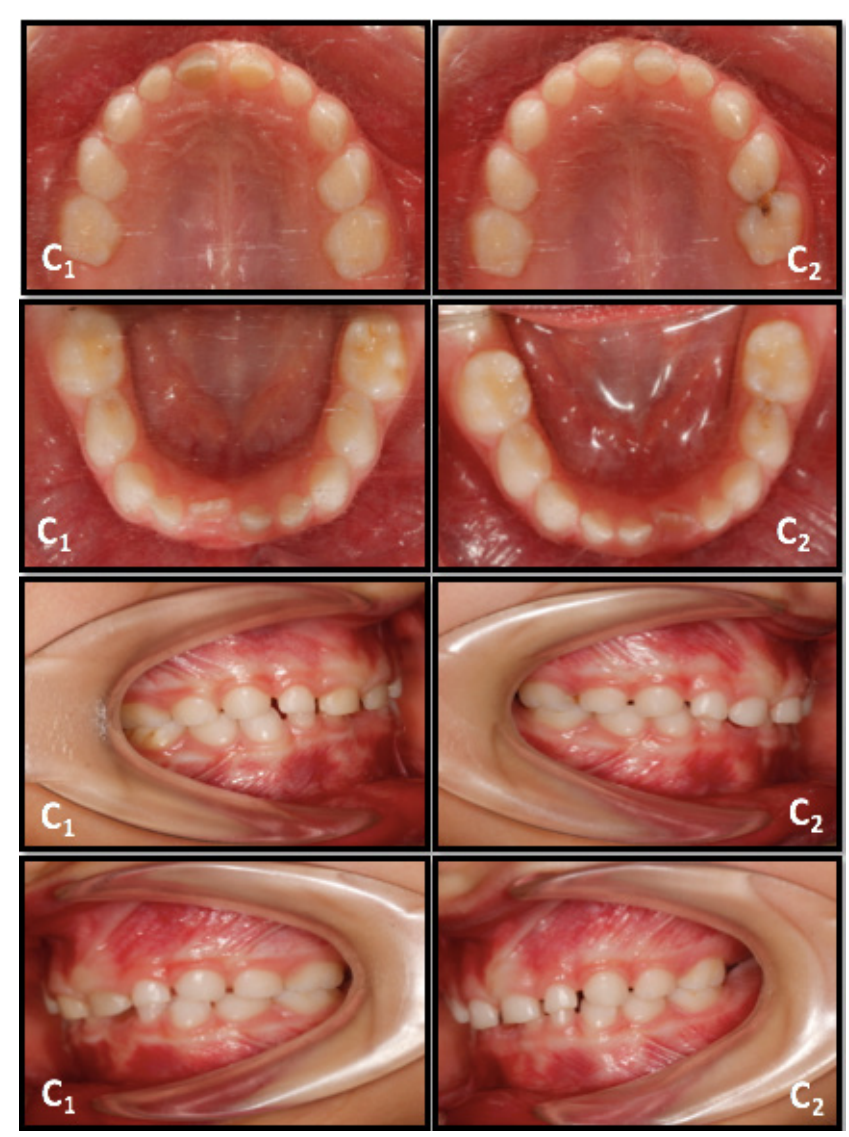

Fig. 8. Intraoral photographs of $C_{1}$ and $C_{2}$
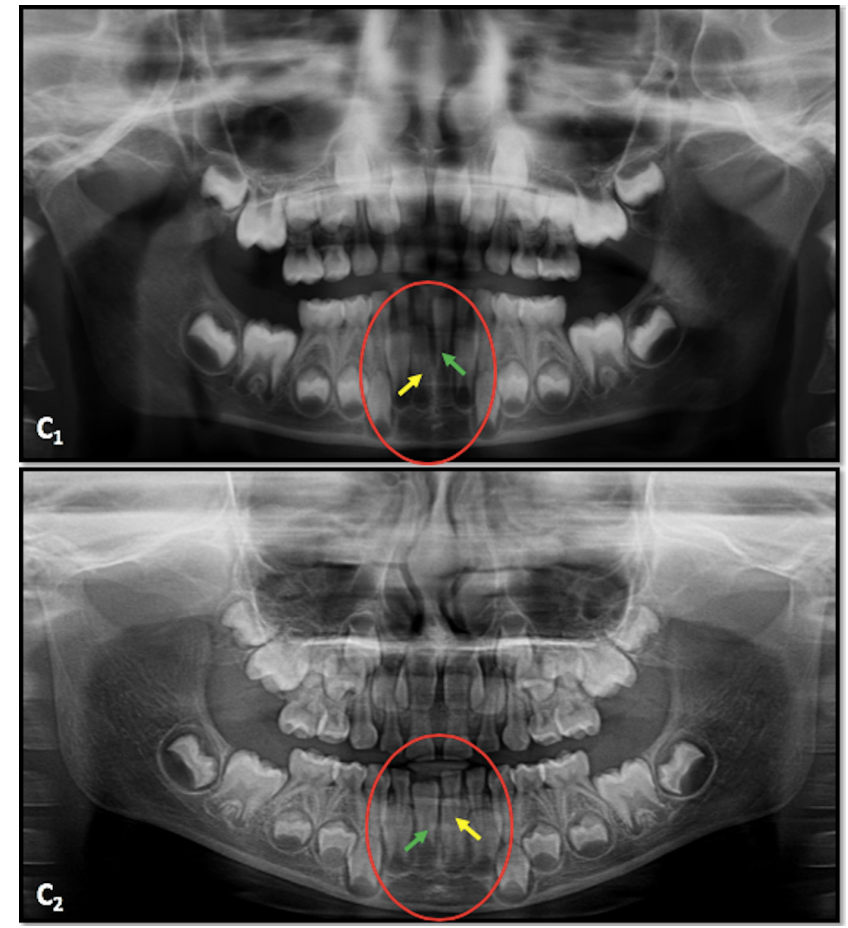

Fig. 9. Panoramic radiographs showing the Ml dental features of $C_{1}$ and $C_{2}$ (arrows)

\section{Discussion}

Mirror imaging - a special manifestation of twinning, also referred to as reverse asymmetry - occurs in MZ twin pairs, who are considered to have identical features. ${ }^{9}$
Rather than an epiphenomenon, MI is considered a biological polarization that describes the role of biochemical, genetic, psychological, and environmental factors in the occurrence of not only reverse asymmetry, but also opposite tendencies in the development of personality, sex orientation as well as psychiatric and pathological conditions. ${ }^{2,13}$

The exact biological pathways of this polarization are still not clearly understood. Mirror-image asymmetries are believed to occur as a result of the blockage of predetermined cells, leading to the establishment of a second reversed morphogenetic gradient. ${ }^{9}$ Also, the maldistribution of the homeobox genes which define the anterior-posterior axis and the early molding of the embryo during splinting has been reported to deteriorate regulatory balance. ${ }^{14}$ Another explanation of MI is the timing of the cleavage of the zygote, and therefore the type of placentation. ${ }^{2}$ Regarding placentation, MZ twins can be grouped as dichorionic/diamniotic (cleavage occurring $1-5$ days post-conception, before implantation), dichorionic/monoamniotic (cleavage occurring 6-9 days post-conception, after implantation) and monochorionic/monoamniotic (late cleavage, probably occurring 9-10 days post-conception $^{2,5}$ ) It has been noted that the basic symmetry of the embryo occurs at around 7-8 days, when the amnion is differentiating. ${ }^{4}$ If the zygote divides in late embryogenesis, this may result in asymmetries, and the incomplete redefinition of these asymmetries may lead to discordance for the left-right orientation and different degrees of MI in MZ twin pairs. ${ }^{4,9}$ However, according to BadzakovaTrajkov et al., the occurrence of MI asymmetries is largely due to chance. ${ }^{15}$

The MI phenomenon typically affects the tissues derived from the ectodermal layer, which develops early. ${ }^{1,6}$ Although situs inversus or heterotaxy syndrome have been reported in internal organs, this phenomenon rarely affects mesodermally derived organs. ${ }^{14,16}$ Mirror-image ectodermal features, such as the tooth eruption pattern, eyesight, hair whorls, dermatoglyphics, the laterality disturbances of the cerebral hemispheres, and non-right handedness are frequently observed in MZ twin pairs. ${ }^{1,3,6}$ Mirror-image handedness is presumed to be a reflection of variations in cerebral lateralization among twins. ${ }^{4}$ Nearly $30 \%$ of the reported MZ twin pairs have MI handedness. ${ }^{5}$ In the present cases, only twins $\mathrm{A}_{1}$ and $\mathrm{A}_{2}$ presented discordant handedness. Also, MI hair whorls were observed in twins $B_{1}$ and $B_{2}$.

The bilateral symmetrical development of dentition commences at about 4 weeks in utero and extends until physical maturity at about 21 years post-natally. Thus, dentation provides a good model to explore the fascinating phenomenon of MI. ${ }^{1,4}$ Dentition is strictly under genetic control. Thus, MI asymmetries in dental features provide insight into genetic control over phenotypic expression, and also other etiologic factors of the asymmetric developmental mechanisms in MZ twins. ${ }^{9}$ 
Mirror-image dental fusion, hypodontia, germination, and supplemental teeth have been reported in the literature. ${ }^{9,10}$ Song et al. reported a case of twins presenting with hip cysts, who also had an MI crossbite in their dentition. ${ }^{2}$ They suggested that, depending on the degree of MI, multiple organ systems can be affected; thus, if one of the MZ twins presents with a medical problem, it may be logical to perform a diagnostic workup on the other twin as well. ${ }^{2}$ In all 3 of our cases, MI dental features were detected in the tooth eruption patterns and impaction.

Mirror-imaging pathological conditions have also been noticed in MZ twins. Zhou et al. described a pair of MZ twins who developed MI arachnoid cysts in the temporal fossa. ${ }^{6}$ The MI first and second branchial arch syndrome associated with cleft lips and palates was reported in $\mathrm{MZ}$ twins by Satoh et al. ${ }^{7}$ In another case report, Brent described the surgical management of twins who were afflicted with MI unilateral microtia. ${ }^{8}$

Even when physical characteristics are concordant, MI monozygotic twins can exhibit discordance in psychiatric conditions. Lohr and Bracha reported a twin pair in which one was diagnosed with bipolar disorder and the other with schizophrenia. ${ }^{17}$

In conclusion, the MI phenomenon may cause biological polarization, reflected in twin pairs as reverse asymmetrical physiological features or pathological conditions, in different degrees. Our report on 3 cases of $\mathrm{MZ}$ twins with MI dental features contributes to the understanding of the limitations of genetic control over dental phenotypic expression and possible epigenetic origin. We also suggest that twin pairs who show 1 or more MI features should be examined extensively for medical, dental and psychological asymmetry.

\section{ORCID iDs}

Damla Torul (1) https://orcid.org/0000-0003-2323-606X Mehmet Melih Omezli (1) https://orcid.org/0000-0002-6606-6593

\section{References}

1. Hughes TE, Townsend GC, Pinkerton SK, et al. The teeth and faces of twins: Providing insights into dentofacial development and oral health for practising oral health professionals. Aust Dent J. 2014;59(Suppl 1):101-116.

2. Song J, Song A, Shim A, Kim E, Song M. Mirror-image identical twins presenting in mirror-image hip cysts: A case report and review of the literature. Rheumatol Curr Res. 2013;S17:001.

3. Sommer IE, Ramsey NF, Bouma A, Kahn RS. Cerebral mirror-imaging in a monozygotic twin. Lancet. 1999;354(9188):1445-1446.

4. Townsend $G$, Richards $L$. Twins and twinning, dentists and dentistry. Aust Dent J. 1990;35(4):317-327.

5. Townsend GC, Richards L, Hughes T, Pinkerton S, Schwerdt W. The value of twins in dental research. Aust Dent J. 2003;48(2):82-88.

6. Zhou JY, Pu JL, Chen S, Hong Y, Ling CH, Zhang JM. Mirror-image arachnoid cysts in a pair of monozygotic twins: $A$ case report and review of the literature. Int J Med Sci. 2011;8(5):402-405.

7. Satoh K, Shibata $Y$, Tokushige $H$, Onizuka T. A mirror image of the first and second branchial arch syndrome associated with cleft lip and palate in monozygotic twins. Br J Plast Surg. 1995;48(8):601-605.

8. Brent B. Repair of microtia with sculpted rib cartilage grafts in identical, mirror-image twins: A case study. Ann Plast Surg. 2011;66(1):62-64.
9. Sperber GH, Machin GA, Bamforth FJ. Mirror-image dental fusion and discordance in monozygotic twins. Am J Med Genet. 1994;51(1):41-45.

10. Beere D, Hargreaves JA, Sperber GH, Cleaton-Jones P. Mirror image supplemental primary incisor teeth in twins: Case report and review. Pediatr Dent. 1990;12(6):390-392.

11. Kaprio J, Sarna S, Koskenvuo M, Rantasalo I. The Finnish Twin Registry: formation and compilation, questionnaire study, zygosity determination procedures, and research program. Prog Clin Biol Res. 1978;24(Pt B):179-184.

12. Bishop DVM. Handedness and specific language impairment: A study of 6-year-old twins. Dev Psychobiol. 2005;46(4):362-369.

13. Golbin A, Golbin Y, Keith L, Keith D. Mirror imaging in twins: Biological polarization - an evolving hypothesis. Acta Genet Med Gemellol (Roma). 1993;42(3-4):237-243.

14. Sommer IE, Ramsey NF, MandI RC, Kahn RS. Language lateralization in monozygotic twin pairs concordant and discordant for handedness. Brain. 2002;125(Pt 12):2710-2718.

15. Badzakova-Trajkov G, Häberling IS, Corballis MC. Cerebral asymmetries in monozygotic twins: An fMRI study. Neuropsychologia. 2010;48(10):3086-3093.

16. Thacker D, Gruber PJ, Weinberg PM, Cohen MS. Heterotaxy syndrome with mirror image anomalies in identical twins. Congenit Heart Dis. 2009;4(1):50-53.

17. Lohr JB, Bracha HS. A monozygotic mirror-image twin pair with discordant psychiatric illnesses: A neuropsychiatric and neurodevelopmental evaluation. Am J Psychiatry. 1992;149(8):1091-1095. 